\title{
THE EFFICIENCY OF CONTRACTUAL ARRANGEMENTS IN PRIVATE AGRICULTURAL PRODUCT MARKETS
}

\author{
Haleigh Boyd, Lewis Evans and Neil Quigley*
}

The electronic and information revolution is changing virtually all aspects of economic and social life, no more so than in the ability of firms of all sizes to make their mark in production and exporting. The ready access to vast information and the lower costs that now attend dealing with other firms have opened opportunities that never before would have been cost effective at the individual firm level. These firms have to contract with other firms for all sorts of purposes. Because of the small size of agricultural and horticultural producers and special problems of seasonal production, variability in production and price, and product perishability, some of the most challenging contracts are in this sector.

Co-operatives provide a vehicle for the vertical integration of production and processing in agriculture. The producers provide capital for and control the processing entity so that their interests are aligned. Returns to producers bundle together the commodity price and the return from the capital invested in processing.

Many of the agricultural product markets in New Zealand operate within this co-operative structure, and in the case of the dairy industry it is supported by statute. The forestry, wine and processed vegetable industries are notable exceptions in that these industries employ contracts between producers and processors as an alternative to vertical integration via co-operatives.

* Haleigh Boyd isan economic analyst at Arthur Andersen, Lew Evans is Professor of Economics and Executive Director of the New Zealand Institute for the Study of Competition and Regulation, Neil Quigley is Professor of Economics and Dean of the Faculty of Commerce and Administration at Victoria University of Wellington.

Acknowledgements: funding for this project was provided by the New Zealand Government Producer Board Project Team. Lizzie Chambers made a valuable contribution to the first stage of this project. The paper has benefited from the comments of an anonymous referee. 
In this article we use examples of contracts between producers and processors in the forestry, wine and processed vegetable markets to consider the extent to which contracts may provide efficient vehicles for the alignment of interests between producers and processors in agricultural markets. We consider the ways in which these contracts:

-Minimise transaction costs;

-Use incentive mechanisms and monitoring to limit opportunism;

-Allocate risk;

-Facilitate investment in specific assets; and

-Allocate property rights.

We assess the implications of the annual crop cycles and perishability of grapes and vegetables with the longer crop cycles of forestry. We conclude that contracts appear to be viable alternatives to co-operative structures, even in the market for perishable agricultural products.

\section{INTRODUCTION}

The electronic and information revolution is changing virtually all aspects of economic and social life. No more so than in the ability of firms of all sizes to make their mark in production and exporting. The ready access to vast information and the lower costs that now attend dealing with other firms have opened opportunities that never before would have been cost effective at the individual firm level. These firms have to contract with other firms for all sorts of purposes. Because of the small size of agricultural and horticultural producers and special problems of seasonal production, variability in production and price, and product perishability, some of the most challenging contracts are in this sector.

Co-operatives provide a vehicle for the vertical integration of production and processing in agriculture. Vertical integration internalises the contracting problems between processors and producers, but requires that producers commit capital to processing and complicates entry to and exit from agricultural production. Recent debate about producer board reform in New Zealand has raised questions about how deregulation may affect co-operative arrangements between primary producers and the processors who purchase their crop. In particular, concerns have been raised about the removal of statutory support for co-operative structures in the dairy industry, and the ability of private contractual arrangements to substitute for them.

New Zealand's most prominent examples of producer-processor co-operatives occur in dairying. The Dairy Board has a statutory monopoly over the export of all milk products 
from New Zealand. A majority of the directors of the Board are elected by "qualifying companies" which must be co-operatives. Other companies or co-operatives that do not wish to export through the Dairy Board may apply to the Board, but they have no certainty that a permit will be granted. ${ }^{1}$

Dairy producers have limited milk-holding capacity and processors have processing plant that is of a certain scale. These are specific assets that are critical to transactions between them. Historically this has been solved in New Zealand by co-operative vertical integration where producers own, in rough proportion to the milk supplied, the processing activity. Dairy production and processing may have particular characteristics that make vertically integrated producer co-operatives the efficient organisational structure. A critical test of whether these features require a co-operative structure is whether agricultural industries with similar features can be organised using contractual arrangements as an alternative to co-operative vertical integration.

In this article we present the results of a study of arrangements between growers and private processors in agricultural industries where there is no co-operative or monopoly export (producer board) structure imposed by statute. Our discussion is based on examples of contracts currently in use in three important New Zealand agricultural sectors that operate without industry specific support: wine, processed vegetables, and forestry. Each of these industries is an export success story for New Zealand and is characterised by multiple processing/exporting companies and a large number of independent growers. Summaries of the key provisions of the contracts can be found in the Appendix.

\section{AGRICULTURAL PROCESSING AND THE THEORY OF CONTRACTS}

There are few empirical studies of agricultural contracts in the academic literature, ${ }^{2}$ and most of these are devoted to sharecropping arrangements between landowners and farmers. ${ }^{3}$ To our knowledge there have been no dedicated studies of arrangements between growers and the purchaser of their crop. Consequently, we have built the theoretical structure of this paper upon the literature on the economic theory of contract.

1 See the Dairy Board Act 1961 and its subsequent amendments.

2 BR Lyons provides a useful review of empirical work on inter-firm contracts across a wide range of industries: see "Empirical Relevance of Efficient Contract Theory: Inter-Firm Contracts" (1996) 12 Oxf Rev Econ Policy 27.

3 See for example DW Allen and D Leuck "Contract Choice in Modern Agriculture: Cash Rent Versus Cropshare" (1992) $35 \mathrm{~J}$ of L and Econ 397; DW Allen and D Leuck (1992) 8 J of L, Econ and Organization 366 . 
The terms and conditions agreed by parties to a contract establish their legally enforceable rights and responsibilities. From the perspective of economics, contracts provide five key ingredients of transactions: ${ }^{4}$

(1) A transactions cost-minimising framework providing mutual benefits to parties contracting in the presence of bounded rationality and incompleteness. Contracts will be incomplete because it will only be feasible to explicitly include a limited range of contingencies in each contract. ${ }^{5}$ First, bounded rationality dictates that not all contingencies can be foreseen, nor their effect on the contract evaluated. Furthermore, contracts are costly to negotiate, write and enforce. Even if all contingencies were known, the transaction costs of negotiating and writing less relevant (or unverifiable and unenforceable) terms into the contract may exceed the benefits of their inclusion. ${ }^{6}$

(2) Limitations on opportunistic behaviour. As Posner has observed, "... the fundamental function of contract law ... is to deter people from behaving opportunistically toward their contracting parties, in order to encourage the optimal timing of economic activity and ... obviate costly self-protective measures."7 Because the potential for opportunism is pervasive, all contracts establish explicit or implicit constraints on the actions of parties. Contracts typically contain a balance of incentive payments and provisions for monitoring that minimise the scope for opportunisim. Normally, the more reliance placed on incentives, the lower are monitoring costs.

(3) An allocation of risk between parties to the contract. Because it is not possible to control the realisation of states of the world, contracts allocate risk both explicitly and implicitly. Risks are allocated between parties in a manner that, ceteris paribus, has parties that are more willing and able to carry risk assuming more risk relative to other parties. The terms of the contract will embody compensation for the risk explicitly and implicitly assumed by each party.

4 For a detailed analysis matching long-term contracts with key characteristics of transactions see DJ Goddard "Long-Term Contracts: A Law and Economics Perspective" [1997] NZ L Rev 423.

5 S Shavell "Contracts" in New Palgrave Dictionary of Law and Economics (MacMillan, London, 1998) 436-445.

6 B Salanie The Economics of Contracts: A Primer (MIT Press, Cambridge (Mass), 1997).

7 RA Posner Economic Analysis of Law (4 ed, Little, Brown \& Co, 1992) 91. 
(a) A framework within which parties to the contract may undertake investment in specific assets. Transaction-specific investments are those which cannot easily be transferred to other uses. Specific investment encompasses human assets, dedicated assets and brand-name capital in addition to physical assets. Site specificity and temporal specificity also make assets less valuable outside of a relationship. ${ }^{8}$

(b) An allocation of property rights between the parties to the contract. Property rights are defined as the right to consume, obtain income from and alienate assets. A central function of contracts is to specify enforceable rights to relevant assets at each point in time. ${ }^{9}$

While we analyse each of these separately, we recognise that contractual provisions regarding one factor will reflect contractual provisions of another. Contracts reflect tradeoffs between risk, incentives, monitoring and transaction costs. Ultimately, the efficiency of a contract will be the outcome of the contract as a whole.

\section{TRANSACTION COST MINIMISATION}

\section{A Theory}

Transactions costs and bounded rationality have several implications for the form and content of contractual arrangements. First, the terms of the contract will cover a limited range of issues that are essential to the transaction. We expect the detail and complexity of those provisions to be kept to a minimum. Furthermore, where the contractor engages in multiple transactions, we expect a set of standard contracts and terms that avoid the costs of negotiating individual relationship-specific contracts, with limited scope for customisation to individual circumstances.

The transactions costs of enforcing contracts will depend both on the legal system and the reputation of parties to each contract. It is generally accepted that reputation may act as a non-legal mechanism for the enforcement of contractual obligations ${ }^{10}$ because a reputation for opportunistic behaviour will determine the terms on which parties are prepared to enter contracts in the future.

8 OE Williamson "Opportunistic Behaviour in Contracts" in New Palgrave Dictionary of Law and Economics (MacMillan, London, 1998) 703-710.

9 Y Barzel Economic Analysis of Property Rights (Cambridge University Press, Cambridge, 1989).

10 See for example D Gambetta Trust: Making and Breaking Cooperative Relations (Clarendon Press, Oxford, 1988) 291-304. 
The importance of the reputation mechanism depends on whether profitable trade is expected to continue into the future. If the discounted present value of future gains from continued trade with the same partner exceeds the short-term benefits of breach, then a rational party will honour the contract even setting aside legal considerations. Trading prospects with other parties in the industry may be included in this evaluation if the firm's wider reputation could be damaged through bad publicity. Lyons has observed that where reputation is important, contracts will tend to be less formal and legalistic. ${ }^{11}$

In general the duration of a contract should cover the length of the event contracted for in order to minimise transaction costs. An exception is where some form of long-term specific investment exists. Then the duration of the contract will often extend over the life of the investment in order to protect the investor from potential hold-up (see part IV A below).

If contracts were complete, the ability to renegotiate would tend to bring efficiency losses because it implies that terms of the contract are not committed to at the time the contract is written. In contrast, renegotiation is often beneficial in an incomplete contractual relationship because it allows the parties to respond to contingencies that were initially unconsidered in the contract. However it is important that the key features of contracts generally do not change as information is revealed ex post, otherwise this will affect the time consistency of contracts and reduce their enforceability. If renegotiation does take place the intent of the contract should be maintained. ${ }^{12}$

\section{B Application}

\section{Content and form}

Our evidence is consistent with the theory in demonstrating that to reduce negotiation costs processors tend to use one or more standard contracts for each type of transaction. For example, grapegrowers are offered one of two standard contracts. The only term that differs between the two is that pertaining to the payment schedule: one offers a negotiated price per tonne, the other a price calculated as a function of the average price of wine produced from the particular grape variety in the previous year. Contracts in the forestry industry exhibit many variations in pricing structure, point of sale and other conditions. However a range of standard terms exist for each which are "mixed and matched" to make up a contract.

11 Lyons, above $\mathrm{n} 2$.

12 Shavell, above $\mathrm{n} 5$. 
The contracts considered in this study are also consistent with theory in their standardised format and lack of attention to specific contingencies. Evidence to support this contention lies in the fact that the three vegetable contracts are remarkably similar in their format, content and language although they serve different processors and crops. This indicates that only the basic necessary terms for such a transaction are written into the contract. Between the industries, however, there are noticeable differences in the form of the grower-processor contracts.

The tone of forestry contracts is markedly different from that of agreements with vegetable and grapegrowers. Forest-harvesting contracts contain many more general legal terms than their vegetable and grape counterparts and are comparatively more detailed and tightly worded. The provisions in the sweetcorn, tomato and grape contracts are relatively less formal. In particular, we note differences in the disputes resolution clauses. Although the vegetable/grape contracts contain standard disputes provisions, it is agreed by both growers and processors that these are rarely invoked. In contrast, detailed disputes procedures are outlined in both forestry contracts we have access to.

These observations are consistent with the proposition that reputation may act as an enforcement mechanism in the vegetable and grape industries, but that legal enforcement is more important in forestry. The rationale behind this assertion relies on differences in both the nature of the grower-processor relationship and the grower's relationship with the rest of the industry. These differences indicate that a forestry processor will stand to lose less business through reputation damage caused by a breach of contract than will a vegetable processor or a winemaker. Therefore, reputation is less likely to provide incentives for the forestry company to abide by the terms of the contract. Legal enforcement will be relied upon, thus explaining the relative formality of forestry contracts.

The nature of the grower-processor relationship is very different in forestry than it is in the vegetable processing and wine industries. Both vegetable processors and winemakers rely on the grower's crop for much of their inputs to production and relationships with their growers are generally frequently repeated and longstanding. In contrast, an agreement between a forestry company and a particular small woodlot owner tends to be a one-off transaction. Furthermore, such purchases make up a relatively minor part of an integrated forestry company's business. Thus one could argue that the loss of any future dealings with a single small forest owner poses little threat to the forestry processor, but to a vegetable processor or winemaker the loss may be enough to outweigh any short-term gains from breaching the contract.

Growers also play different roles in each industry. Small woodlots are often owned for investment purposes by individuals or firms whose main occupations are outside the forestry industry. In contrast, a tomato or grape grower is likely to be more involved with 
the industry on a day-to-day basis. Thus it is conceivable that, compared to a vegetable/grape grower, a small forest owner will have limited industry networks through which any opportunistic behaviour by the processor could be revealed. Consequently, significant damage to trading prospects with other parties in the industry is improbable. However, a winemaker's wider reputation may be damaged as a result of dishonouring a contract with a single grower, and this may act as a further incentive for them to act in accord with the intent of the contract.

It should be noted that these conclusions are also valid in the case of potential contract breach by the grower. A small woodlot owner would not be as concerned to preserve a good reputation within the industry as would a grape or vegetable grower, and thus nonlegal enforcement mechanisms are unlikely to be important.

\section{Duration}

Where significant long-term specific investment is absent from these grower-processor relationships, we expect the duration of contracts to cover the length of the crop cycle. This was found to be the case with annual crops (sweetcorn and tomatoes), where contracts are entered into at the beginning of each season on an annual basis.

Contracts between grapegrowers and winemakers carry a minimum term of three years. They remain valid for five years and then are terminable by either party with one year's notice. Although grapes are harvested annually, the minimum term of three years corresponds to the length of time required to properly establish new grapevines. The first two to three years are critical to the long-term well being of the vines and ultimately to the quality of the fruit. The minimum term is then probably best explained by the processor's quality control and monitoring requirements than by a specific investment argument.

Radiata pine takes 25 to 30 years to reach maturity, however grower-processor contracts do not extend over the full crop cycle. They typically cover only the harvesting period itself and are usually entered into a matter of months before logging begins. The short term of these contracts allows both parties to minimise their exposure to risks associated with the high volatility of market prices, conditions and opportunities within the industry. However, this was not always the case. When the government was the major owner of plantation forests, long-term supply contracts (of 20 to 30 years) with processing companies were common. These were intended to encourage and protect specific investment in assets such as mills and processing plants by securing their supply of logs. However, nowadays both buyers and sellers are reluctant to enter into such lengthy commitments. This can be explained by changes to the composition of the industry in recent years. Log availability has increased, both in terms of number of suppliers and harvest volumes, thus reducing the need to secure supply. 


\section{Renegotiation}

Factors particular to the forestry industry provide an explanation for the fact that only the forest stumpage contract contains provisions for renegotiation. Initial stumpage prices are renegotiated every three months and the agreement is terminated if the parties cannot settle on new prices. It is preferable that the parties are given the opportunity to reassess the situation periodically in this manner, as opposed to attempting to consider all possible changes in the state of the market at the time the contract is written. Either party may choose to terminate the contract at the renegotiation point if conditions are unfavourable. The forestry industry is unusual in that forest maturity is flexible. There is a window of approximately five years during which the timber can be harvested, so the forest owner is under no pressure to harvest all timber at once. Thus it is optimal that they should be able to get out of the contract when market conditions are poor.

\section{LIMITATIONS ON OPPORTUNISM: INCENTIVE MECHANISMS AND MONITORING}

\section{A Theory}

The value of a transaction is affected by the level of effort expended by one or both parties to a contract. No contractual difficulties are presented where the behaviour of a party alters only his or her own costs or benefits. However, incentive problems may arise if there are effects on the value of the relationship to the other party.

For example, the effort and care a grower devotes to the crop influence its ultimate value to the processing company. Thus the processor must find a way to ensure that the grower does not neglect the crop without having to monitor the grower at all times, which would be excessively costly. Ideally, the grower and processor would agree on the optimal level of effort and explicitly include this in the provisions of the contract. Unfortunately, it is exceedingly difficult to precisely characterise the level of effort required in a manner that is verifiable in court. Effort is unobservable. Thus the desired level of effort cannot be directly specified in the contract. However, the processor can encourage effort of the grower by relating grower remuneration to some effort-dependent measure through incentive mechanisms. An optimal contract will use incentive mechanisms and/or monitoring in order to restrict opportunistic behaviour by the grower at minimum cost.

Incentive mechanisms base the grower reward on something observable and measurable, for example quality measures. They have the feature that performance is rewarded directly, for example under piece-rates for harvesting the harvester is paid for each unit harvested. Incentives better align the interests of growers and processors and therefore reduce the costs of processor monitoring. The importance of incentives increases in proportion to the dependence of transaction value on growers' actions. 
However, because quality is not entirely attributable to factors within the grower's control, payment based entirely on observed quality is likely to place too much risk on the grower. Due to this trade-off between incentives and risk sharing, mixed payment schedules composed of a base price and an incentive-related margin are common.

To summarise, the value of the contract to the processor is dependent on both the quality and quantity of the crop. The grower is able to influence both quantity and quality to a certain extent. Because we cannot explicitly contract for optimal effort on the part of the grower, and costs of continuous monitoring are high, we would expect contracts to include incentive mechanisms for quality and quantity, as well as processor monitoring provisions. However, incentive mechanisms should be balanced with consideration for the grower's attitude to risk. ${ }^{13}$

\section{B Application}

The primary issue to consider when evaluating the implications for contract design of potential opportunistic behaviour within a relationship is: to what extent do the grower's actions after the contract has been entered into affect the value of the transaction to the processor? On this basis, we can separate our discussion of vegetable and grape growerprocessor contracts from that relating to timber contracts.

\section{Vegetables and Grapes}

In all vegetable and grape supply arrangements, the grower's behaviour, from when the land is prepared at the beginning of the contract term right through to harvest, significantly influences the ultimate quality and quantity of crops. However, their influence on final crop value is concentrated at certain times during the year: around planting/sowing and at harvest. Thus it is cost-effective for the processor to concentrate its monitoring procedures during these periods, rather than distribute their efforts equally throughout the growing season. The sweetcorn, tomato and grape contracts all support this notion, specifying that the company's field staff will supervise and co-ordinate sowing/planting, as well as arrange harvest. Furthermore, the processor supplies inputs crucial to the ultimate value of the crop (for example seeds/plants).

In addition to processor monitoring and input specification, contracts also provide incentive mechanisms in order to minimise opportunistic behaviour throughout the year. Incentives for the grower to maximise both quality and quantity were found in all contracts. Quantity incentives are provided because base prices and quality-adjusted

13 P Milgrom and J Roberts Economics, Organization and Management (Prentice-Hall, Englewood Cliffs (NJ), 1992). 
prices are invariably specified "per tonne", so that the total payment to growers is dependant on yield volume.

Grower-processor contracts for grapes and vegetables also incorporate incentive mechanisms where payment is somehow related to the quality of the mature crop. For example, grape quality is determined by brix (sugar) levels. The price per tonne received by the grape grower is dependent on the average brix level at harvest. Of note is the fact that the brix-price relationship differs below and above target brix: price increases more steeply between the target and maximum brix levels than between the minimum and target brix levels. That is, per unit brix differential, growers are rewarded more for an increase in quality than they are punished for a fall in quality. This payment schedule reflects the trade-off between providing strong incentives for good quality, while at the same time minimising the risks to the grower of producing a below-target quality yield (see also Part III B above).

Grapegrowers are also offered an alternate payment scheme, whereby the price per tonne is related to the average price of wine produced from that particular grape variety in the previous year. This mechanism provides a direct link between the value to the processor and the benefit to the grower.

While all three vegetable contracts make deductions from the total harvested crop weight for defects, only one sweetcorn contract offers different prices per tonne based on quality (which is also measured by brix levels at harvest). Both the other sweetcorn contract and the contract for tomatoes specify a single price per tonne. This is possibly explained by the fact that brix levels are crucial to the value of the winemakers' end products. Therefore it is important enough to provide strong incentives for high brix levels that the costs of differential payment and brix measurement are justified. The importance of sweetcorn/tomato brix levels (or a similar quality measure) may not be as high.

\section{Timber}

As contracts for timber purchase are generally entered into towards the end of the crop cycle (rather than at the beginning), possible incentive problems are very different from those that occur in the case of contracts for supply of annual crops.

The efforts of grape and vegetable growers during the term of the contract significantly affect the value of the crop (as measured by the quality and quantity of that crop). Potential for grower opportunism is mitigated by incentives for both quality and quantity in the payment schedule, as well as via monitoring by the processor.

On the other hand, while a forest owner's actions also have a substantial effect on the ultimate quality of the timber, these decisions are made well before contracting occurs. After a timber-harvesting contract has been written (shortly before harvest), the forest 
owner has relatively little influence on the final value of the logs. Although the forest owner's payment is based on the quality of the logs produced, this purpose of this feature is not to alter grower behaviour during the term of the contract. Similarly, there are no contractual provisions for monitoring by the processor. Although it is specified in the agency agreement that the owner must "maintain the forest pending harvest", this provision is merely a legal clause which is not monitored and is enforced only in extreme circumstances.

In fact, it is the actions of the purchasing company which are likely to affect log value, through the care taken during the harvesting and marketing processes. Therefore the contracts need to guard against opportunistic behaviour on the part of the processor, rather than the grower.

The processor's efforts may affect both the quality of the logs harvested from the forest and, in the case of the agency agreement, the actual sale price received for them. The "quality" of logs is determined by well-defined grading systems. The forest owner can do little to affect final log grades during the contractual period, however the care taken by the loggers during harvesting is crucial to the resultant value of the products. Relative to other industries, forestry harvesting is a very complex and lengthy procedure. In addition to minimising physical damage to the wood, the harvester must optimise log making and ensure that the logs are promptly delivered to the mill for treatment. ${ }^{14}$ Additionally, under a forest agency contract the processor effectively sells the logs on behalf of the owner. Thus in this case the processor's marketing efforts also affect the timber value to the owner.

Incentive mechanisms are crucial to these types of timber-harvesting contracts for several reasons. First, as set out above, the realised value of the grower's woodlot is highly dependant on the efforts of the processor. In addition, the contract is likely to represent a one-off transaction for the small forest owner, while the processing company engages in such arrangements very frequently. Thus information about forest harvesting and sales is held very asymmetrically and monitoring costs for the grower will be high.

The nature of the stumpage contract ensures that incentive problems at harvest are few. Ownership of logs is transferred to the processor on removal from the forest, ensuring that the forest owners' and processors' interests are aligned with respect to maximising the

14 Harvesting is typically carried out by third-party logging contractors engaged by the processing company. However, the loggers are extensively monitored by the processor's quality control staff. In the interests of clarity, we shall ignore issues relating to arrangements between logging contractor and processor and for now assume them to be one and the same party. 
quality of the forest out-turn. Forest agency contracts provide similar incentives through the payment scheme: the processor's remuneration includes a percentage margin on actual sale price (which is dependent on log grades).

However, the interests of the two parties will differ with regard to preserving the value of the land during harvesting. For this reason the contracts explicitly include provisions whereby the processor must take measures to minimise problems such as soil erosion and waste left on the property, and meet local authority requirements in this respect.

\section{ALLOCATION OF RISK}

\section{A Theory}

There are several categories of exogenous risk relevant to contracts for supply of agricultural products:

- Market prices are often volatile; thus the prices that will be prevailing at the time of harvest are often unknown when the contract is written (price risk).

- The volume and the quality of crop from a given planted area are variable and often affected by uncontrollable factors (yield risk).

- Given the saliency of prompt harvest at maturity for most agricultural products, the many factors that may interfere with or prevent timely harvest also present a significant source of uncertainty (harvest risk).

Third-party insurance may be taken out to manage such risks, but contracts can also be used to allocate risk between parties. An optimal contract should allocate risks according to the parties' relative attitudes to risk. ${ }^{15}$ While it is difficult to accurately gauge each party's attitude to risk, we can often make some broad generalisations based on characteristics of each party and of the transaction.

A party that is risk averse will prefer a smoother income stream to more variable income, even if their expected income is lower as a result. Where one or both parties are risk averse, the party that is more willing to accept risk (that is, is less risk averse) should bear a larger proportion of risk. The terms of the contract should incorporate compensation for this higher level of risk.

The provisions for risk sharing are especially important to the efficiency of the contract where the value of the exchange is large relative to the wealth of one or both parties and if risks are large. Both of these factors generally apply to grower-processor contracts.

15 Shavell, above $\mathrm{n} 5$. 
The trade-off between incentives and monitoring that exists in contracts is heightened by concerns about risk sharing. High piece-rate incentives put more risk on the grower, but the grower will generally be more risk averse than the processor. However, lower incentives imply higher monitoring costs for the processor. Therefore these trade-offs are an important feature of contract design. ${ }^{16}$

\section{B Application}

\section{Attitudes to risk}

Although attitudes to risk cannot be precisely measured, we assume that in general the individual grower is more risk averse than the processing company. The reasoning behind this assumption is as follows. First, the contract for a particular crop may represent the farmer's entire annual income, whereas the company is involved in many other transactions. These include the company's dealings with many other growers of that crop. In effect the processor is diversified and thus their exposure to farm-specific risk is negligible.

Furthermore, even for a single type of crop, a large company with national operations will also be less concerned with regional risks such as those related to weather conditions (for example droughts and isolated hail storms). Additionally, the company is likely to process other types of crop and may also have interests in different lines of business. All of these factors act to decrease the processor's sensitivity to risk relative to an individual grower.

A further consideration in the case of the forestry industry is the fact that for a small forest owner, the exchange is likely to be of a one-off nature, whereas the purchasing company repeatedly engages in such contracts as part of their daily business. ${ }^{17}$

Given that the grower is assumed to be more risk averse than the processor, we expect that the contract will allocate risk so that the processor assumes a larger risk burden unless this is precluded by other efficiency considerations.

\section{Risk allocation}

Various types of agricultural risk have been identified, each of which are considered in relation to actual contract design. Third-party insurance against these risks is generally the

16 Milgrom and Roberts, above n 13.

17 KB Leffler and RR Rucker "Transaction Costs and the Efficient Organisation of Production: A Study of Timber-Harvesting Contracts" (1991) 99 J of Pol Econ 242. 
responsibility of the grower up to the point where ownership is transferred to the processor (see part V). However the grower is under no obligation to take up such insurance. Within the contracts, allocation of risk is achieved via the payment schedules as well as through clauses that make explicit the parties' liabilities in the event that specified circumstances should arise.

Allocations of each of the three sources of agricultural risk (price risk, yield risk and harvest risk) will be considered in turn.

\section{(a) Price Risk}

A contract which fixes base piece-rates at the beginning of the transaction assigns the risk associated with changes in spot prices to the buyer. In contrast, an arrangement where grower remuneration is related to variable market conditions at a later date exposes the grower to price risk.

Vegetable processors are willing to set prices at the time the seasonal contracts are written (approximately one year in advance) and thus assume the risk of spot market price variability. Grapegrowers have the choice of two payment arrangements. In the first case, winemakers specify per-tonne prices when the contract is written. Alternatively, grapegrowers can choose to share price risk via a payment scheme reflecting the ex-winery prices of the previous period.

The stumpage contract prices set by the forestry company, however, apply for a mere three months before they are renegotiated. This feature reflects the volatile nature of $\log$ prices on the commodity market and allows both parties to reassess their position throughout the term of the contract (see part I B above). When stumpage contracts are entered into far in advance, the stumpage prices are sometimes based on key market variables (such as the log prices and exchange rates) at the time of harvest.

The provisions of the forest agency contract, on the other hand, do not shield the grower from fluctuations in market prices in the period between initial contracting and final sale. This type of contract uses a mixed payment scheme, whereby the managing company receives a percentage of the final sale price as well as a fixed amount per unit sold. The owner must also reimburse the manager for operating costs and then receives the residual sale proceeds. Thus the forest owner faces considerable risk of movements in log prices, exchange rates, shipping rates and logging costs. However, the forest owner is compensated for this larger degree of risk, in that the company is prepared to accept lower margins when they can share the burden of price risk.

\section{(b) Yield Risk}

Perhaps the most obvious source of variation in grower income is variation in the volume and condition of the mature crop itself. Incentive-based payment schemes are 
often conditional on both quantity and quality. This practice, while encouraging optimal effort, imposes a further degree of risk on the grower.

There are many factors that may affect crop yield. Many of these are within the grower's control to a certain extent. Even the adverse effects of exogenous risks such as hailstorms or pests can be minimised by the grower's efforts. For example, some forms of crop disease may be prevented by spraying and measures can be taken to minimise weather damage to the crop. An ideal contract must provide incentives and/or monitoring provisions to ensure that these precautions will be taken. However, there remains a residual risk of yield losses that the grower cannot prevent.

Quantity and quality incentives, found in all contracts, were discussed in part IV B above. Quantity incentives take the form of "per tonne" prices, so that grower income varies in direct proportion to the weight of crop yield. All else equal, each individual grower will prefer to maximise the volume of their mature crop.

However, from the processor's perspective, there is a limit to the amount of produce they will desire at the pre-agreed price (which is based on the estimated aggregate yield of all their growers). With this in mind the grape and tomato contracts specify a target tonnage, rather than just a fixed acreage (which is the case in the sweetcorn contracts). Volume produced above this amount may still be purchased, but not necessarily on the same terms. The revised price is negotiated once the total production from all growers is known, allowing the processor to set appropriate marginal rates. This represents a form of risk sharing.

Some contracts also include quality incentive margins on a base price. For example, the price per tonne received by grapegrowers is dependent on the average brix level at harvest. The differential brix-price relationship above and below the target brix level reflects the trade-offs between incentive mechanisms and risk-sharing (see part IV B 1 above).

In addition to quality incentive margins, quality standards and weight deductions for defects, vegetable contracts contain a "lost crop" clause. This provision clarifies that the grower will not be compensated for crops that are deemed to be unsuitable for processing due to weather conditions, pests and diseases, incorrect spraying, excessive weeds or Force Majeure. This clause limits opportunism (for example not bothering to spray properly) but at the same time allocates a lot of exogenous risk to the relatively risk averse grower.

\section{(c) Harvest risk}

For many perishable crops, there is a small window during which harvest must take place in order to maximise the value of the crop. Contracts should specify the 
responsibilities of each party if timely harvest is impaired or prevented. The source of the impediment will determine which party should be liable for resultant costs incurred.

The sweetcorn contracts provide an illustration of provisions that can be used to allocate harvest risk. Two distinct causes of harvest disruption are identified. First, the "bypass clause" is invoked when the processor has insufficient capacity to harvest all crops promptly at maturity. Under this provision, growers whose crop is passed over are compensated based on the average yield for that variety. In effect, the "bypass clause" recognises the potential for opportunistic behaviour on the part of the processor. If the clause did not exist, there would be an incentive for processors to contract for excessive production to ensure they could always operate at full capacity. However, reputation considerations would also act to discourage such a practice.

Adverse weather conditions may also interfere with or prevent harvest. However, as is the case with weather effects on crop yield, the processing company does not assume this risk. Growers are not compensated at all if harvest is completely prevented by the weather. Additionally, if harvest is possible but problematic, the grower must pay the costs of any special harvesting equipment that may be required.

The contracts also state that the grower may elect not to harvest in poor weather in order to avoid damage to the land, but will receive no compensation from the processor. This is an efficient solution as the grower would only choose to exercise this right if the long term costs of damage were expected to exceed their short-term profits from harvesting the crop. Because the contract is short term, if the grower did not have this right, then the processor might make the choice whether to harvest or not without regard for the damage to the land. Furthermore, if the processor fully compensated the grower when they elected not to harvest, then the grower would choose not to harvest if there were any possibility of damage at all.

Forestry stumpage contracts also contain a clause that allocates harvest risk. There are few temporal issues in relation to timber harvesting, however the harvest process is complex and many opportunities for damage to the timber and land can arise. Timber harvesting is typically carried out by third party logging contractors, rather than by the buyer or the seller. Therefore the provision which requires the contractors to insure the forest against damage during harvest is necessary, as during this time possible hazards are largely uncontrollable by either the buyer or seller and monitoring would be excessively costly. This provision provides the logging contractors with incentives to take care during harvest. 


\section{FACILITATION OF INVESTMENT IN SPECIFIC ASSETS}

\section{A Theory}

The problems associated with investment in specific assets may be illustrated by the situation in which a seller invests in a specific asset to be used in the production of goods for a particular buyer. Once the investment has been made, there is a danger that the buyer may attempt opportunistic price renegotiations. This is known as the hold-up problem. Anticipation of this type of behaviour may result in inefficient types and/or amounts of investment. ${ }^{18}$

There are two possible solutions to this problem. Contractual provisions can be used to protect the seller from opportunistic behaviour and encourage the optimal level of investment. For example, a study of United Kingdom franchise contracts found provisions whereby the franchiser must buy back fittings at a predetermined price if the relationship is discontinued. ${ }^{19}$

Alternatively, the seller can invest in the specific asset instead of the buyer and so make the optimal investment himself or herself. This phenomenon has been observed in many industries. For example, car assemblers have been found to own specific physical assets used by their component manufacturers. ${ }^{20}$

\section{B Application}

The primary specific asset relevant to the grower-processor transaction is the specialist equipment required to harvest the crop. In the case of vegetable and grape supply contracts, harvesting equipment is generally owned by the processing company. This result is consistent with expectations for three reasons.

First, as the equipment is of a fairly specialised nature, a grower would be subject to hold-up if he or she were to purchase the costly machinery for his or her own use. The hold-up problem is solved if instead, the processor makes the investment.

Second, it is more efficient that the processor owns the machinery due to economies of scale. An individual grower will only have use for such equipment once a year, whereas the processor can use the equipment to service multiple growers. This problem alone

18 OE Williamson The Economic Institutions of Capitalism (Free Press, New York, 1985).

20 K Monteverde and DJ Teece "Appropriable Rents and Quasi-Vertical Integration" (1982) $25 \mathrm{~J}$ of L and Econ 321. 
could be alleviated if several growers were to purchase the machinery on a co-operative basis and this practice is in fact observed in many areas of agriculture.

However, a further factor to be considered in the investment decision is the processor's quality control requirements. Harvesting practice significantly affects the final value of the crop. It is difficult for the processor to monitor the level of care taken during harvest when it is conducted by the grower or a third party. For this reason many processors will not accept crop that has not been harvested by themselves or by their agents.

The three arguments in favour of processor-owned harvesting equipment also apply to grower-processor relationships in forestry. Moreover, the fact that the small forest owner is likely to require logging resources for a single, once-off harvest rules out the possibility of investment by the grower himself or herself. However, logging equipment is almost invariably provided by third party logging contractors rather than by the processing company itself. Many industries now contract out non-core operations in this way, largely motivated by the efficiency of specialisation. The nature of forestry harvesting provides further reasons to explain why contracting is preferred.

A forestry company experiences more variability in harvest volumes than a vegetable processor. Thus a forestry company who owns their own logging equipment bears large risks of finding itself with excessive or deficient harvesting capacity. Consider a sweetcorn processor who enters into contracts with many growers at the beginning of the season. The processor can then estimate how much harvest capacity will be required and at which locations, one year in advance. In contrast, forest purchase agreements are often entered into at short notice, so that the harvest capacity that will be required at one time is less certain.

In fact, at one time it was common for forestry processors to control their own logging resources, however they are now reluctant to invest such a large amount of capital in resources which could often (and unpredictably) be under-utilised or over-stretched. Logging contractors are free to service many forestry companies, leading to economies of scale and the smoothing out of capacity requirements over time in the aggregate.

The existence of the "bypass clause" in sweetcorn contracts indicates that vegetable processors face similar problems of harvest capacity shortfalls and there are indications which suggest that third party harvesting contractors are sometimes used in this industry for that reason.

\section{ALLOCATION OF PROPERTY RIGHTS}

\section{A Theory}

In the case of agricultural grower-processor contracts, the crop itself is the principal asset to which rights must be assigned. The point in time at which ownership is 
transferred from the grower to the processor should be specified clearly in the contract. The point of ownership transfer that is chosen should ideally be that which minimises transaction costs.

\section{B Application}

Although we found examples of contractual provisions to allocate intellectual property rights and rights to plant varieties, the chief asset applicable to all grower-processor relationships is the crop itself.

One would expect that a contract for crop supply would specify the point at which ownership of the crop in question is transferred from one party to the other. However, ownership of the crop was not mentioned at all in several cases. These apparent deficiencies are consistent with observations about the varying nature of grower-processor relationships (and thus contracts) for different crops (see part I B above). Vegetable contracts, several of which did not specify the point of ownership transfer, were found to be less formal, legalistic and detailed. It may be that in these relationships, ownership is understood to be transferred when the processor receives the crop, so that formal specification is unnecessary.

Whether explicitly specified or not, processors generally appear to assume ownership of vegetables and grapes on delivery, following sampling and acceptance of the crop. The choice of this point balances the desire to transfer title as soon as possible after the processor takes physical possession of the crop (as grower monitoring then becomes difficult), with the requirement that the processor must first ensure that quality standards have been met.

Similarly, forestry stumpage contracts specify that ownership of timber is passed to the processor as they pay for it (that is, as they remove it). Ownership is never really transferred to the agent under a "sell-on-behalf-of" contract, as the company remains accountable to the grower until the logs are finally sold. However, "for legal purposes" the agent is considered to be responsible for the timber after "severance from stump", that is, once they take physical control of the wood.

Of note is the fact that a stumpage contract involves the sale of the right to harvest the standing timber, rather than property rights to the harvested crop itself. It has been acknowledged that this method of production in fact minimises transaction costs. ${ }^{21}$

Consider the transactions costs of a woodlot owner facing a choice between:

21 Leffler and Rucker, above n 17. 
(1) engaging logging contractors to harvest the timber and then selling it to a forestry company; or

(2) selling the cutting rights to the standing timber to a forestry company.

A third-party logging contractor has little incentive to maximise the quality of harvested logs or to work efficiently, and monitoring is very costly. If instead the owner sells the standing timber, the forestry company bears the costs of any inefficiencies in harvesting and thus has incentives to keep such losses to a minimum.

Thus the transfer of rights to the timber on removal from the forest, rather than on delivery to the processor, will be the transaction cost minimising option. This conclusion has empirical support. In a study of 200 timber contracts, not one forest owner had elected to hire loggers and subsequently sell the harvested logs. ${ }^{22}$

\section{CONCLUSION}

Our findings suggest that in agricultural industries where vertical integration is absent, contracts are effective in establishing relationships between producers and processors and in addressing issues such as risk sharing, monitoring and incentives, and opportunism in the face of specific investment. Vineyards are long-lived specific assets and grapes have to be harvested at a critical point in time. Vegetable processing uses specific harvesting and processing equipment, although in this case the farmers' holdings of specific assets are limited. A unique feature of forestry is the one-off nature of the harvest, but again the contracts that we have studied incorporate features designed to address the risk, transaction costs and potential for opportunism associated with forestry.

The contracts considered in this paper do not support the contention that the transactions between producers and processors require vertical integration through a cooperative structure. $^{23}$ Specific assets, perishability and other contractual problems identified in the dairy industry are not unique to it. In the contracts that we have studied these problems have been addressed by contractual provisions that make for efficient

22 Leffler and Rucker, above $\mathrm{n} 17$.

23 Hansmann stresses product homogeneity as a necessary condition for an efficient co-operative structure: Henry Hansmann The Ownership of Enterprise (Belknap Press of Harvard University Press, Cambridge (Mass), 1996). 
contracts between producers and processors. ${ }^{24}$ There are a variety of agency problems associated with the co-operative structure arising from the muted incentives for specialised activity, and the mechanisms of control, that arise in co-operative structures. ${ }^{25}$ These suggest that there are trade-offs in co-operative structures that will render them efficient in certain circumstances and not others.

Our evidence on contracts does not provide conclusive proof that co-operatives could be eliminated from the dairy industry. It does however suggest that further legislative change to the dairy industry should remove any statutory regimen that provides nonneutral incentives for the co-operative organisational structure; if co-operatives are the efficient means of organising the dairy industry they would require no shoring up by means of legal statute. Their voluntary formation would provide the appropriate test of any comparative advantage that existed in the co-operative structure. Permitting the freedom for organisational structures to evolve is extremely important in the currently rapidly changing environment that is opening up opportunities for firms of all sizes.

24 In order to glean some assessment of the transaction efficacy of grower contracts we examined the number of contract disputes relating to grower or vertical contracts reported in the New Zealand Law Reports for 1996-2000. There were no such cases for processed vegetables, wine or forestry. For dairy there were some disputes, but a large fraction of them were to do with trademark issues: none concerned co-ordination of production and processing.

25 See Hansmann, above n 23, ch 7 and Philip K Porter and Gerald W Scully "Economic Efficiency in Cooperatives" (1987) $30 \mathrm{~J}$ of L and Econ 489. 
TABLE 1

Wine Grapes

(a) Duration of contract (I) The contract is for five years, with a minimum term of three years. The contract is terminable by either party with one year's notice. Grapevines take three to four years to establish, with success being largely dependant on the first two to three years.

(b) Nature of relationship (I) Although contracts are for three to five years, relationships between growers and winemakers tend to be longstanding.

(c) Nature of contract (I) There are a number of standard contracts, which are transferable by mutual agreement.

(d) Disputes Procedure (I) There is a standard arbitration clause, however this is rarely used.

(e) Price Determination* (II)

- The contract is for a specified tonnage of grapes, for which a base price per tonne is negotiated when the contract is signed (approximately one year before harvest). Terms of sale may be negotiated for grapes in excess of the contracted tonnage or of sub-standard quality.

- This base price is conditional on a specified target brix (sugar) level, which is measured at harvest. Within a specified range, a margin is added to that base price for each percentage increase in brix, and deducted for each percentage decrease in the sugar levels. Of note is the fact that the price-brix relationship is different above and below target brix: price increases more steeply between the target and maximum brix levels than between the minimum and target brix levels.

- There are clearly specified quality criteria with regard to factors such as rot and disease, spray residues and foreign material. Grapes that do not meet these minimum standards and/or the minimum brix level, will not be accepted on the agreed terms.

*Growers are also offered an alternative payment scheme whereby the price per tonne is calculated by the company's auditor, and is a function of the ex-winery average price of wine produced from the particular grape variety in the previous year. A quality bonus scheme also applies to this option. 
Table 1 continued

(f) Monitoring Requirements/Inputs (II) There is evidence of extensive winery field staff involvement, especially in the period closer to harvest. Furthermore, it is becoming increasingly common for winemakers to supply vineyards with new vines on the condition that they have a right to buy the vintage from those vines for a certain number of years.

(g) Risk Allocation (III) Risk passes to the winemaker "on truck". Prior to this point, the grower is responsible for insuring the crop.

(h) Specific Assets (IV) No specific assets are identified in the contract.

(i) Property Rights/Ownership Transfer (V) Ownership of the grapes is transferred from grower to processor on acceptance of the grapes at the winery.

Note

The number in brackets indicates the main part of the article in which the aspect is discussed. 
TABLE 2

\section{Sweetcorn (Processor A)}

(a) Duration of contract (I) The contract is an annual, corresponding with the sweetcorn crop cycle.

(b) Nature of relationship (I) Although contracts are seasonal, they are often renewed each year before planting.

(c) Nature of contract (I) All contracts are based on a standard framework, with some variation in terms across different regions and crops. The contract is not tradable, as growers and their land must be individually approved.

(d) Disputes Procedure (I) There is a standard arbitration clause, however this is rarely used.

(e) Price Determination (II)

- A single base price per tonne is specified in the contract. There is no set contracted tonnage. The price per tonne is slightly reduced according to cartage distance from the factory.

- Deductions are made from the total weight based on incidence of defects (for example damage, insects, rot and disease) found in random samples.

(f) Monitoring Requirements/Inputs (II)

- Seed is supplied by the processor at the beginning of the season, and the cost of seed is deducted from the gross payment to the grower following harvest. If the processor's preferred sowing contractor is used, the cost of sowing will be recovered by the company in the same manner as seed.

- The processor must approve most aspects of horticultural practice, for example land preparation, sowing and spraying. They may also advise on other matters. Harvesting is arranged by the processor. 


\section{(g) Risk Allocation (III)}

- Growers are not compensated for "lost crops" (defined as crops damaged by weather conditions, pests and diseases, incorrect spraying, excessive weeds or Force Majeure; where the grower fails to provide a spray diary; or in the case that the growers elects for the crop not to be harvested during adverse weather conditions to avoid damage to their land).

- However, the processor will compensate the grower for "by-passed crops", which arise where the company has not harvested the crop at maturity (for reasons other than those which lead to "lost crops"). Compensation is based on the average yield for that variety, but the total compensation to growers for by-passed crops in a season is limited to five per cent of that season's total corn payments.

(h) Specific Assets (IV) All specialist harvesting equipment is owned and operated by the processor.

(i) Property Rights/Ownership Transfer (V) Ownership is transferred to the processor immediately following sampling and acceptance by the company.

Note

The number in brackets indicates the main part of the article in which the aspect is discussed. 
TABLE 3

\section{Sweetcorn (Processor B)}

(a) Duration of contract (I) The contract is annual, corresponding with the sweetcorn crop cycle.

(b) Nature of relationship (I) Although contracts are seasonal, they are often renewed each year before planting.

(c) Nature of contract (I) All contracts are based on a standard framework, with some variation in terms across different regions and crops. The contract is not tradable, as growers and their land must be individually approved.

(d) Disputes Procedure (I) There is a standard arbitration clause.

(e) Price Determination (II)

- Base prices per tonne for each grade are specified in the contract. The grade of the corn is determined by its brix level, measured at harvest. There is no set contracted tonnage. The price per tonne is slightly reduced according to cartage distance from the factory.

- A minimum of five per cent is deducted from the total weight of the harvested crop to allow for defects, stalk, leaf, and so on.

(f) Monitoring Requirements/Inputs (II)

- $\quad$ Seed is supplied by the processor at the beginning of the season, and the cost of seed is deducted from the gross payment to the grower following harvest.

- The processor must approve most aspects of horticultural practice, for example land preparation, sowing and spraying. They may also advise on other matters. Harvesting is arranged by the processor. 


\section{(g) Risk Allocation (III)}

- Growers are not compensated for "lost crops" (defined as crops damaged by weather conditions, pests and diseases, Force Majeure, etc.; crops that cannot be harvested due to field conditions; or where the growers elects for the crop not to be harvested during adverse weather conditions to avoid damage to their land). Costs incurred if specialist harvesting equipment is required due to adverse weather are deducted from the grower's payment. Similarly, the grower must bear the additional expenses incurred if access is inadequate at harvest.

Table 3 continued

- However, the processor will compensate the grower for "by-passed crop", which arises where the company has not harvested the crop at maturity due to strikes, breakdowns or insufficient plant capacity. If total compensation for by-passed crops in a season is less than 2.5 per cent of crop proceeds, then the remainder is distributed amongst growers.

(h) Specific Assets (IV) All specialist harvesting equipment is owned and operated by the processor.

(i) Property Rights/Ownership Transfer (V) The point of ownership transferal from grower to processor is not specified in the contract.

Note

The number in brackets indicates the main part of the article in which the aspect is discussed. 


\section{Tomatoes (Processor A)}

(a) Duration of contract (I) The contract is an annual, corresponding with the tomato crop cycle.

(b) Nature of relationship (I) Although contracts are seasonal, they are often renewed each year before planting. Tomato-based products represent a significant part of Processor A's business. There now have only a small number of large contract tomato growers. Prices are negotiated at an annual meeting with all tomato growers.

(c) Nature of contract (I) All contracts are based on a standard framework, with some variation in terms across different regions and crops. The contract is not tradable, as growers and their land must be individually approved.

(d) Disputes Procedure (I) There is a standard arbitration clause, however these are rarely used.

(e) Price Determination (II)

- The contract is for a specified tonnage of tomatoes, for which a base price per tonne is negotiated when the contract is signed (approximately one year before harvest). Terms of sale may be negotiated for tomatoes in excess of the contracted tonnage or of sub-standard quality.

- Deductions are made from the total weight based on incidence of defects (for example damage, insects, rot and disease) found in random samples. There are also defined minimum tolerance levels of specified diseases and defects.

- Payments to growers are staggered over several months.

(f) Monitoring Requirements/Inputs (II) The processor must approve horticultural practices such as land preparation, sowing and spraying. They may also advise on other matters, as well as supply seed or plants. Harvesting and planting is arranged by the processor.

(g) Risk Allocation (III)

- Growers are not compensated for "lost crops" (defined as crops damaged by weather conditions, pests and diseases, incorrect spraying, excessive weeds, or Force Majeure.).

(h) Specific Assets (IV) All specialist harvesting equipment is owned and operated by the processor. 
Table 4 continued

\section{(i) Property Rights/Ownership Transfer (V)}

- Ownership of the crop is passed to the company immediately following sampling and acceptance by the company.

- The contract also specifies that the grower shall have no rights over supplied plants deemed as proprietary varieties. Growers may not sell seeds, plants, or fruit of these varieties to other parties.

Note

The number in brackets indicates the main part of the article in which the aspect is discussed. 
TABLE 5

Forest Agency Agreement

(a) Duration of contract (I) The contract has a specified commencement date, and continues until all standing trees are harvested, unless the agreement is terminated earlier. There is also an expiry date, at which point the contract is terminated regardless of whether all trees have been harvested or not. It is entered into a maximum of around three years before harvest, but often only a matter of months before logging begins.

(b) Nature of relationship (I) For small forest lot owners, the sale of a standing forest would tend to be a one-off transaction.

(c) Nature of contract (I) All contracts are based on a standard framework, with some variation in terms. A number of standard legal terms are included in the provisions of the contract. The contract is not tradable, but is transferable by either party with the written consent of the other.

(d) Disputes Procedure (I) There is a standard arbitration clause.

(e) Price Determination (II)

- The manager receives a management fee of two components: a) a percentage margin of the sale price; and b) a fixed amount per unit sold (JAS, tonnes, or cubic metres) for overheads.

- The manager is also reimbursed for all direct costs and operating expenses.

- $\quad$ The owner receives the net sale proceeds.

(f) Monitoring Requirements/Inputs (II) The contract specifies that the forest owner must maintain the forest pending harvesting, however this is not monitored and is only enforced in exceptional circumstances.

(g) Risk Allocation (III) Insurance responsibility is negotiable: the manager can assume responsibility from the point of "severance from stump" if the owner so desires, however generally the owner continues to insure the wood (although the manager must take "reasonable care" at all times).

(h) Specific Assets (IV) Machinery and equipment tends to be provided by logging/roading contractors. 
Table 5 continued

(i) Property Rights/Ownership Transfer (V) For legal purposes, ownership is transferred to the manager at the point of "severance from stump", however this is not mentioned in the contract.

Note

The number in brackets indicates the main part of the article in which the aspect is discussed. 
TABLE 6

Forest Stumpage Agreement

(a) Duration of contract (I) The contract has a specified commencement date, and continues until all standing trees are harvested, unless the agreement is terminated earlier. There is also an expiry date, at which point the contract is terminated regardless of whether all trees have been harvested or not. Generally entered into shortly before harvest (typically three months- one year before logging begins).

(b) Nature of relationship (I) For small forest lot owners, the sale of a standing forest would tend to be a one-off transaction.

(c) Nature of contract (I) There are about 10 different standard contracts, from which the various terms can be "mix-and-matched". A number of standard legal terms are included in the provisions of the contract. The contract is not tradable, but is transferable by either party with the written consent of the other party.

(d) Disputes Procedure (I) There is a detailed disputes resolution clause.

(e) Price Determination (II)

- Prices per tonne for different log grades/types are specified in the contract. These prices are renegotiated after three months has passed. Logs are weighed as they come out of the forest, and the owner is paid monthly for all wood removed in the previous month.

- $\quad$ The costs incurred in construction and maintenance of access roads are deducted from the monthly payment.

(f) Monitoring Requirements/Inputs (II) No monitoring or input requirements are specified in the contract.

(g) Risk Allocation (III)

- In this contract, the prices are set in advance but are subject to renegotiation every three months. If the initial prices are set far in advance, they are sometimes based on key market variables (such as the exchange rate, log prices) at the time of harvest.

- The contract contains a clause which states that the logging contractor must take out a "public liability" policy to cover against damage (including fire damage) during harvest. However, the forest owner and the buyer must co-operate in preventing and extinguishing fires. 
- The buyer is responsible for insurance once they assume ownership of the forest products.

Table 6 continued

(h) Specific Assets (IV) Machinery and equipment tends to be provided by logging/roading contractors.

(i) Property Rights/Ownership Transfer (V)

- Title and risk passes to the buyer at the same time and same proportion as the forest products are paid for.

- The contract specifies that all intellectual property rights arising from the harvest will remain with the buyer.

Note

The number in brackets indicates the main part of the article in which the aspect is discussed. 